\title{
Inferior Turbinate Size and CPAP Titration Based Treatment Pressures: No Association Found among Patients Who Have Not Had Nasal Surgery
}

\author{
Macario Camacho, ${ }^{1,2}$ Soroush Zaghi, ${ }^{3}$ Daniel Tran, ${ }^{1}$ Sungjin A. Song, \\ Edward T. Chang, ${ }^{1}$ and Victor Certal ${ }^{4,5}$ \\ ${ }^{1}$ Otolaryngology-Head and Neck Surgery, Division of Sleep Surgery and Medicine, Tripler Army Medical Center, 1 Jarrett White Road, \\ Honolulu, HI 96859, USA \\ ${ }^{2}$ Department of Psychiatry and Behavioral Sciences, Sleep Medicine Division, Stanford Hospital and Clinics, Stanford, CA 94304, USA \\ ${ }^{3}$ Otolaryngology-Head and Neck Surgery, Division of Sleep Surgery and Medicine, Stanford Hospitals and Clinics, Stanford, \\ CA 94304, USA \\ ${ }^{4}$ Department of Otorhinolaryngology, Sleep Medicine Centre, Hospital CUF, 4100-180 Porto, Portugal \\ ${ }^{5}$ Centre for Research in Health Technologies and Information Systems (CINTESIS), University of Porto, 4200-450 Porto, Portugal
}

Correspondence should be addressed to Macario Camacho; drcamachoent@yahoo.com

Received 17 July 2015; Revised 9 December 2015; Accepted 10 December 2015

Academic Editor: Gerd J. Ridder

Copyright (C) 2016 Macario Camacho et al. This is an open access article distributed under the Creative Commons Attribution License, which permits unrestricted use, distribution, and reproduction in any medium, provided the original work is properly cited.

\begin{abstract}
Objective. To evaluate the effect of turbinate sizes on the titrated continuous positive airway pressure (CPAP) therapeutic treatment pressures for patients with obstructive sleep apnea (OSA) who have not had nasal surgery. Study Design. Retrospective case series. Methods. A chart review was performed for 250 consecutive patients. Results. 45 patients met inclusion criteria. The mean \pm standard deviation $(M \pm S D)$ for age was $54.6 \pm 22.4$ years and for body mass index was $28.5 \pm 5.9 \mathrm{~kg} / \mathrm{m}^{2}$. The Spearman's rank correlation coefficient $\left(r_{s}\right)$ between CPAP therapeutic treatment pressures and several variables were calculated and were weakly correlated (age $r_{s}=0.29$, nasal obstruction $r_{s}=-0.30$ ), moderately correlated (body mass index $r_{s}=0.42$ and lowest oxygen saturation $r_{s}=-0.47$ ), or strongly correlated (apnea-hypopnea index $r_{s}=0.60$ and oxygen desaturation index $\left(r_{s}=0.62\right)$ ). No statistical significance was found with one-way analysis of variance (ANOVA) between CPAP therapeutic treatment pressures and inferior turbinate size (right turbinates $p$ value $=0.2012$, left turbinate $p$ value $=0.3064$ ), nasal septal deviation $(p$ value $=0.4979)$, or mask type $(p$ value $=0.5136)$. Conclusion. In this study, CPAP titration based therapeutic treatment pressures were not found to be associated with inferior turbinate sizes; however, the CPAP therapeutic treatment pressures were strongly correlated with apneahypopnea index and oxygen desaturation index.
\end{abstract}

\section{Introduction}

There are several medical [1] and surgical $[2,3]$ treatment options for obstructive sleep apnea (OSA). Patients who use continuous positive airway pressure (CPAP) devices have been shown to have nasal obstruction as a common complaint (estimated prevalence: 25-45\%) [4-6]. As described by Poiseuille's Law, airflow resistance is proportional to the length and is inversely proportion to the radius to the fourth power [7]. Because the radius is such an important variable, small changes, such as a $10 \%$ increase in the cross-sectional area of the nasal cavity airway, can result in a $21 \%$ increase in airflow [8]. Although surgery on the nose has not been shown to dramatically improve OSA [9], it can improve CPAP device use [10].

A recent systematic review and meta-analysis also demonstrated that isolated nasal surgery reduces CPAP device therapeutic treatment pressures by 2-3 centimeters of water pressure (cwp) [10]. Therefore, surgically increasing the size of the nasal airway decreases nasal resistance and reduces CPAP device pressure requirements [10]. However, to our knowledge, for patients who have not undergone 
nasal surgery it is unknown whether patients with smaller turbinates have lower CPAP therapeutic treatment pressure requirements when compared to patients with larger turbinates. A recently published systematic review did not identify any study in the international literature that used inferior turbinate size as a variable in mathematical equations to predict CPAP [11]. For this study we hypothesized that, in patients who have not had nasal surgery, large turbinates would require higher CPAP therapeutic treatment pressures than small inferior turbinates. Because it has previously been shown that nasal surgery can reduce CPAP therapeutic treatment pressures [12], we planned to exclude patients with prior nasal surgery in order to remove this confounding variable. The objective of this study is to evaluate the effect of turbinate sizes on the CPAP titration based therapeutic treatment pressures (in centimeters of water pressure) for patients with OSA who have not previously undergone nasal surgery.

\section{Materials and Methods}

The Stanford Hospital and Clinics Institutional Review Board was contacted and written approval was granted prior to commencing this study. The study design is a retrospective case series evaluating 250 consecutive patients. Inclusion criteria are as follows: (1) Stanford Sleep Medicine Clinic patients who had a nasal examination and underwent an attended in-lab CPAP titration study and (2) the nasal examination needed to include nasal septal deviation severity and inferior turbinate grades for the left and right sides separately. Exclusion criteria are as follows: (1) patients who have undergone nasal surgery. The CPAP titration pressures were obtained based on overnight, in-lab polysomnography. The American Academy of Sleep Medicine (AASM) Manual for the Scoring of Sleep and Associated Events was used by Stanford and outside institutions. The Stanford hypopnea scoring criteria included $\geq 10$ seconds with $\geq 30 \%$ reduction in airflow measured by the nasal flow transducer associated with a 3\% desaturation and/or an electroencephalogram arousal as described in the AASM scoring manual 2013, version 2.0.2 [13].

In order to fully evaluate the effect of inferior turbinate size, a tool ("Inferior Turbinate Classification System, Grades 1 to 4") [12] was utilized. This Inferior Turbinate Classification System provides a method for grading the amount of airway space that the anterior aspect of the inferior turbinate occupies relative to the total available airway space and is summarized as follows: grade 1 is $0-25 \%$ of the total airway space, grade 2 is $26-50 \%$ of the total airway space, grade 3 is $51-75 \%$ of the total airway space, and grade 4 is $76-$ $100 \%$ of the total airway space [12]; see Figure 1. The Nasal Obstruction Symptom Evaluation (NOSE) scale was used to evaluate nasal obstruction and a patient with a score $>40$ was considered to have nasal obstruction [14].

\section{Statistical Analysis}

The data was cataloged using Microsoft Excel 2013 (Redmond, WA, USA). The IBM Statistical Package for Social
Sciences (SPSS) software version 20 (Armonk, New York, USA) was used for statistical analyses. The patient data was analyzed by calculating the means, standard deviations ( $M$ \pm SD), and 95\% confidence intervals [95\% CI]. One-way analysis of variance (ANOVA) was used to evaluate ordinal and nominal data; Spearman's rank correlation coefficient $\left(r_{s}\right)$ was used for continuous data measures. The $r_{s}$ was selected for correlating variables because it is less sensitive to strong outliers and it can also be used for calculating correlation coefficients for both continuous and discrete variables. The standard recommendations for $r_{s}$ strengths were used [15]: $0.0-0.19=$ very weak, $0.20-0.39=$ weak, $0.40-0.59=$ moder ate, $0.60-0.79=$ strong, and $0.80-1.0=$ very strong. Variables evaluated included the CPAP titration data, age, and body mass index (BMI) in kilograms per meter squared $\left(\mathrm{kg} / \mathrm{m}^{2}\right)$, race/ethnicity, apnea-hypopnea index (AHI), oxygen desaturation index (ODI), lowest oxygen saturation (LSAT), inferior turbinate size, nasal septal deviation severity, and other physical exam findings. For CPAP titration pressures, if a fixed pressure was prescribed, that value was used and if pressure ranges were prescribed, then the average of the pressure range was calculated and used as the CPAP therapeutic treatment pressure for analysis purposes. Multivariate analysis was performed using Standard Least Squares Linear Regression. A two-tailed $p$ value $<0.05$ was considered statistically significant.

\section{Results}

A total of 45 patients met study inclusion criteria. The mean \pm standard deviation $(\mathrm{M} \pm \mathrm{SD})$ for age was $54.6 \pm 22.4$ years and for body mass index was $28.5 \pm 5.9 \mathrm{~kg} / \mathrm{m}^{2}$. Table 1 provides demographic information for the patients to include age, AHI, BMI, ODI, LSAT, NOSE Scale scores, race information, nasal septal deviation severity, inferior turbinate size, and mask type. The Spearman's rank correlation coefficient $\left(r_{s}\right)$ between CPAP therapeutic treatment pressures and several variables were calculated and were weakly correlated (age $r_{s}=$ 0.29 , nasal obstruction $r_{s}=-0.30$ ), moderately correlated (body mass index $r_{s}=0.42$ and lowest oxygen saturation $r_{s}=-0.47$ ), or strongly correlated (apnea-hypopnea index $r_{s}=0.60$ and oxygen desaturation index $\left.\left(r_{s}=0.62\right)\right)$. No statistical significance was found with one-way analysis of variance (ANOVA) between CPAP therapeutic treatment pressures and inferior turbinate size (right turbinates $p$ value $=0.2012$, left turbinate $p$ value $=0.3064)$, nasal septal deviation $(p$ value $=0.4979)$, or mask type $(p$ value $=0.5136)$; see Table 2 . The $\mathrm{M} \pm \mathrm{SD}$ for therapeutic CPAP for grade 1 (five patients): $12.8 \pm 2.5 \mathrm{cwp}$, grades $>1$ to 2 (eleven patients): $11.5 \pm 1.6 \mathrm{cwp}$, grades $>2$ to 3 (twenty-one patients): $11.3 \pm$ $1.8 \mathrm{cwp}$, and grades $>3$ to 4 (eight patients): $12.2 \pm 2.9 \mathrm{cwp}$, with a one-way ANOVA $p$ value of 0.4599 ; see Table 3 . Mean diagnostic CPAP titration based treatment pressure by inferior turbinate size (grades 1-4) was evaluated with multivariate analysis with the Standard Least Squares Linear Regression Model with an $R^{2}=0.08, p$ value $=0.9953$ consistent with no association to very weak association; see Figure 2. 


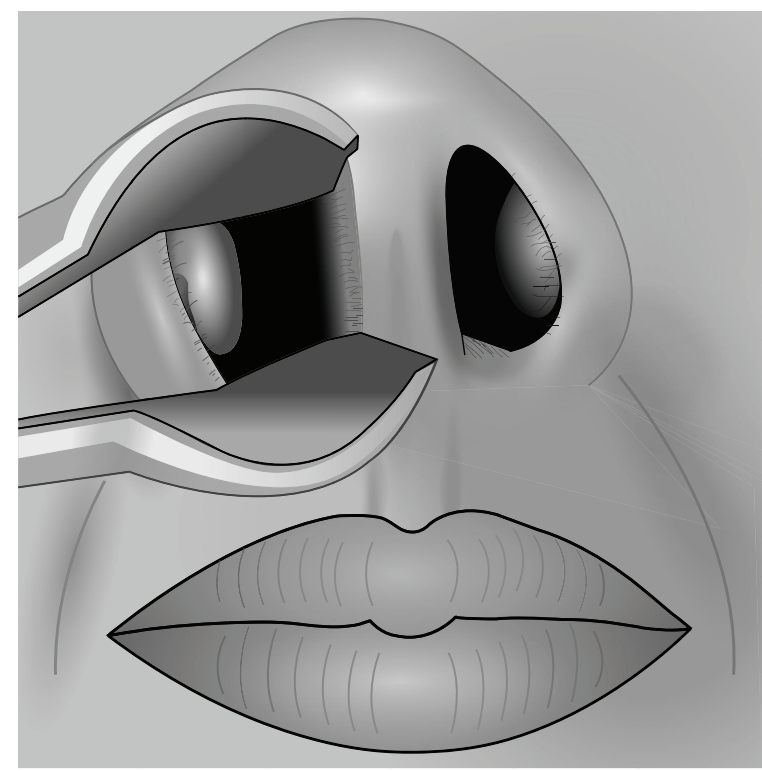

(a)

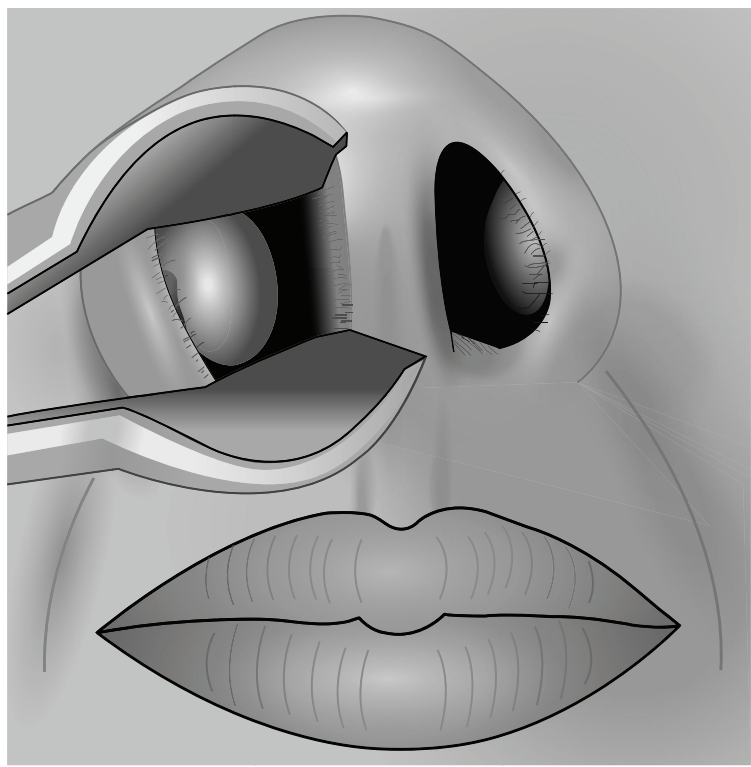

(c)

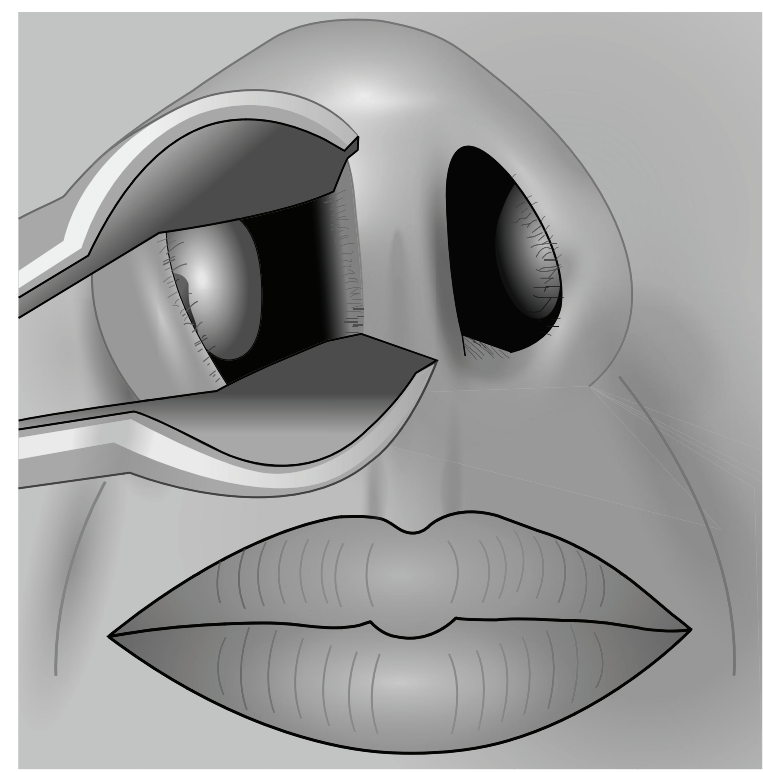

(b)

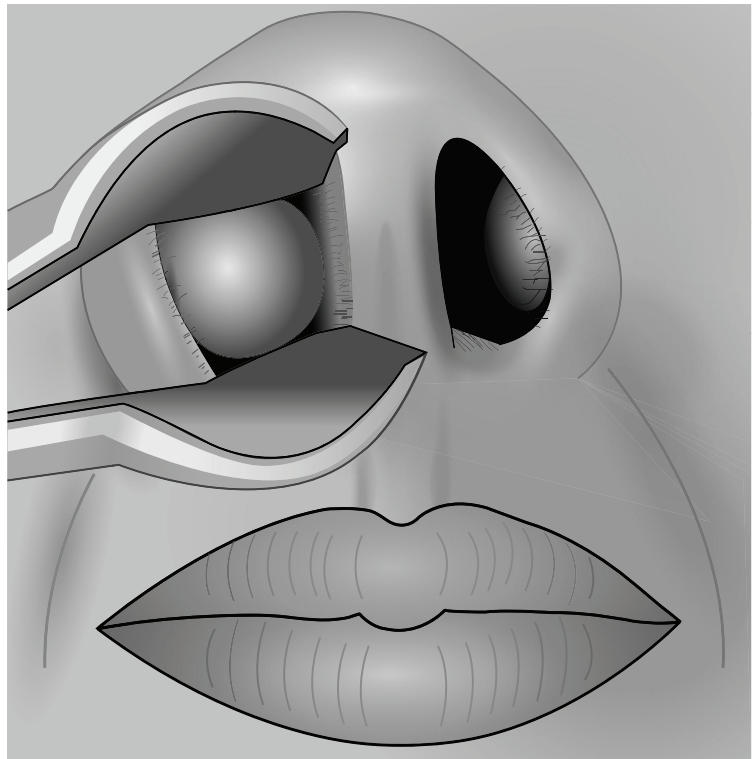

(d)

Figure 1: (a) Grade 1 (0\%-25\% of total airway space). (b) Grade 2 (26\%-50\% of total airway space). (c) Grade 3 (51\%-75\% of total airway space). (d) Grade 4 (76\%-100\% of total airway space). Reproduced with permission [12].

\subsection{Sub-Analyses}

4.1.1. Nasal Obstruction versus No Nasal Obstruction. Among a subgroup analysis of patients without nasal obstruction (as evaluated by a NOSE Scale Score [14] of 40 out of 100 or less, $n=34$ patients) the $\mathrm{M} \pm \mathrm{SD}$ for age was $56.0 \pm 23.8$ years, for body mass index was $28.4 \pm 6.6 \mathrm{~kg} / \mathrm{m}^{2}$, and for inferior turbinate size was $2.47 \pm 0.80$. The $\mathrm{M} \pm \mathrm{SD}$ for CPAP therapeutic treatment pressures for all 34 patients was $11.8 \pm$ $2.2 \mathrm{cwp}$, for grade 1 (four patients): $13.3 \pm 2.7 \mathrm{cwp}$, grades $>1$ to 2 (seven patients): $11.6 \pm 1.7 \mathrm{cwp}$, grades $>2$ to 3 (eighteen): $11.5 \pm 1.8 \mathrm{cwp}$, and grades $>3$ to 4 (five patients) $12.1 \pm 3.5 \mathrm{cwp}$, with a one-way ANOVA $p$ value of 0.5213 ; see Table 3 . For patients with complaints of nasal obstruction (11 patients) the $\mathrm{M} \pm \mathrm{SD}$ for age was $62.5 \pm 15.4$ years, for body mass index was $29.2 \pm 3.5 \mathrm{~kg} / \mathrm{m}^{2}$, and for inferior turbinate size was $2.3 \pm 0.9$. The $\mathrm{M} \pm \mathrm{SD}$ for CPAP therapeutic treatment pressures for all 11 patients was $11.1 \pm 1.3 \mathrm{cwp}$, for grade 1 (one patient): $11 \mathrm{cwp}$, grades $>1$ to 2 (four patients): $11.3 \pm 1.5 \mathrm{cwp}$, grades $>2$ to 3 (three patients): $10.0 \pm 0.0 \mathrm{cwp}$, and grades $>3$ to 4 (three patients) $12.5 \pm 0.7 \mathrm{cwp}$, with a one-way ANOVA $p$ value of 0.4722 ; see Table 3.

4.1.2. Nasal Mask Type. There were three categories in the subanalysis for mask type: unknown mask types (7 patients), nasal masks (27 patients), and oronasal masks (11 patients). 
TABLE 1: Variables for the patients included in the study.

\begin{tabular}{|c|c|c|}
\hline Variables & $N$ & $\mathrm{M} \pm \mathrm{SD}$ \\
\hline \multicolumn{3}{|l|}{ All patients } \\
\hline Age (years) & 45 & $54.6 \pm 22.4$ \\
\hline AHI (events/hr) & 44 & $34.7 \pm 29.4$ \\
\hline BMI $\left(\mathrm{kg} / \mathrm{m}^{2}\right)$ & 45 & $28.5 \pm 5.9$ \\
\hline ODI (events/hr) & 20 & $27.3 \pm 32.7$ \\
\hline LSAT (percent) & 42 & $85.9 \pm 6.2$ \\
\hline \multirow[t]{2}{*}{ NOSE Score (scaled 0-100) } & 45 & $28.9 \pm 22.5$ \\
\hline & & CPAP \\
\hline All patients & 45 & $11.6 \pm 2.0 \mathrm{cwp}$ \\
\hline Asian & 6 & $12.0 \pm 1.4 \mathrm{cwp}$ \\
\hline Black & 3 & $13.3 \pm 3.5 \mathrm{cwp}$ \\
\hline Caucasian & 29 & $11.6 \pm 2.0 \mathrm{cwp}$ \\
\hline Indian & 4 & $11.4 \pm 2.1 \mathrm{cwp}$ \\
\hline Latino & 3 & $9.8 \pm 0.8 \mathrm{cwp}$ \\
\hline Nasal deviation severity & 40 & \\
\hline Grade $1(0-25 \%)$ & 24 & $12.0 \pm 2.3 \mathrm{cwp}$ \\
\hline Grade $2(26-50 \%)$ & 11 & $11.0 \pm 1.6 \mathrm{cwp}$ \\
\hline Grade 3 (51-75\%) & 3 & $10.8 \pm 1.0 \mathrm{cwp}$ \\
\hline Grade 4 (76-100\%) & 2 & $11.0 \pm 1.4 \mathrm{cwp}$ \\
\hline \multicolumn{3}{|l|}{ Inferior turbinate size: right } \\
\hline Grade $1(0-25 \%)$ & 8 & $12.9 \pm 2.0 \mathrm{cwp}$ \\
\hline Grade $2(26-50 \%)$ & 12 & $11.3 \pm 1.5 \mathrm{cwp}$ \\
\hline Grade 3 (51-75\%) & 16 & $11.1 \pm 1.7 \mathrm{cwp}$ \\
\hline Grade 4 (76-100\%) & 9 & $11.8 \pm 2.8 \mathrm{cwp}$ \\
\hline \multicolumn{3}{|l|}{ Inferior turbinate size: left } \\
\hline Grade 1(0-25\%) & 10 & $11.9 \pm 2.1 \mathrm{cwp}$ \\
\hline Grade $2(26-50 \%)$ & 11 & $11.3 \pm 1.8 \mathrm{cwp}$ \\
\hline Grade $3(51-75 \%)$ & 17 & $11.1 \pm 2.0 \mathrm{cwp}$ \\
\hline Grade 4 (76-100\%) & 7 & $12.8 \pm 2.2 \mathrm{cwp}$ \\
\hline \multicolumn{3}{|l|}{ Mask type } \\
\hline Unknown & 7 & $11.3 \pm 1.7 \mathrm{cwp}$ \\
\hline Nasal mask & 27 & $11.8 \pm 2.3 \mathrm{cwp}$ \\
\hline Oronasal mask & 11 & $11.2 \pm 1.5 \mathrm{cwp}$ \\
\hline
\end{tabular}

$\mathrm{AHI}=$ apnea-hypopnea index; $\mathrm{CPAP}=$ continuous positive airway pressure; LSAT $=$ lowest oxygen saturation; $N=$ number of patients in the study with data available; NOSE Score $=$ Nasal Obstruction Symptom Evaluation Scale score; and ODI = oxygen desaturation index.

The $\mathrm{M} \pm \mathrm{SD}$ for CPAP therapeutic treatment pressures for the seven patients with an unknown mask type was $11.3 \pm 1.7 \mathrm{cwp}$; the $\mathrm{M} \pm \mathrm{SD}$ turbinate sizes were $2.66 \pm 0.30$. The $\mathrm{M} \pm \mathrm{SD}$ for CPAP therapeutic treatment pressures for twenty-seven patients with nasal masks was $11.8 \pm 2.3 \mathrm{cwp}$; the $\mathrm{M} \pm \mathrm{SD}$ turbinate sizes were $2.41 \pm 0.96$. For nasal masks, the oneway ANOVA $p$ value of 0.9217 , see Table 3 . The $\mathrm{M} \pm \mathrm{SD}$ for CPAP therapeutic treatment pressures for eleven patients with oronasal masks was $11.2 \pm 1.5 \mathrm{cwp}$; the $\mathrm{M} \pm \mathrm{SD}$ for turbinate sizes was $2.45 \pm 0.82$. For oronasal masks, the oneway ANOVA $p$ value of 0.2732 , see Table 3 .
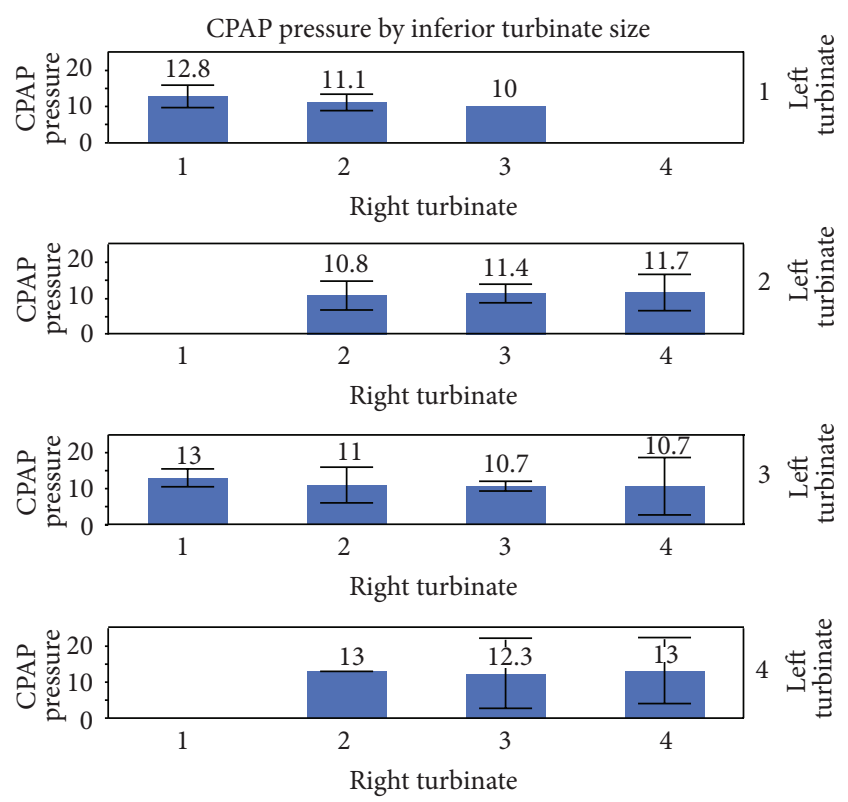

Figure 2: Mean diagnostic CPAP by inferior turbinate size (grades 1-4). Each error bar is constructed using a 95\% confidence interval of the mean. Multivariate analysis with Standard Least Squares Linear Regression Model shows $R^{2}=0.08, p$ value $=0.9953$ consistent with no association to very weak association between CPAP and inferior turbinate size.

\section{Discussion}

There are two main findings to this study. First, CPAP therapeutic treatment pressures do not seem to be influenced by inferior turbinate sizes in patients who have not undergone nasal surgery. It has been shown that patients who have undergone nasal surgery will have a decrease in CPAP therapeutic treatment pressures by approximately 2-3 centimeters of water pressure [10]; therefore, patients with prior nasal surgery were intentionally excluded from the study in order to eliminate this variable as a confounder. The mean diagnostic CPAP and inferior turbinate sizes (grades 1-4) were evaluated with multivariate analysis with the Standard Least Squares Linear Regression Model with an $R^{2}=0.08$, $p$ value $=0.9953$ consistent with no association to very weak association.

Second, other variables were better correlated with CPAP therapeutic treatment pressures. There was a weak correlation between CPAP therapeutic treatment pressures and nasal obstruction using the NOSE Scale questionnaire $\left(r_{s}\right.$ was -0.21 , two-tailed $p$ value 0.57 , not statistically significant) and a very weak correlation for patients without nasal obstruction using the NOSE Scale questionnaire $\left(r_{s}\right.$ was -0.05 , twotailed $p$ value 0.78 , not statistically significant). Given the lack of an association of the inferior turbinate sizes, nasal septal deviation severity, and nasal obstruction overall, these findings suggest that simply observing nasal abnormalities in a patient may not warrant surgery if they do not have complaints of nasal obstruction. Another finding was that lowest oxygen saturation $r_{s}=-0.47$ and body mass index 


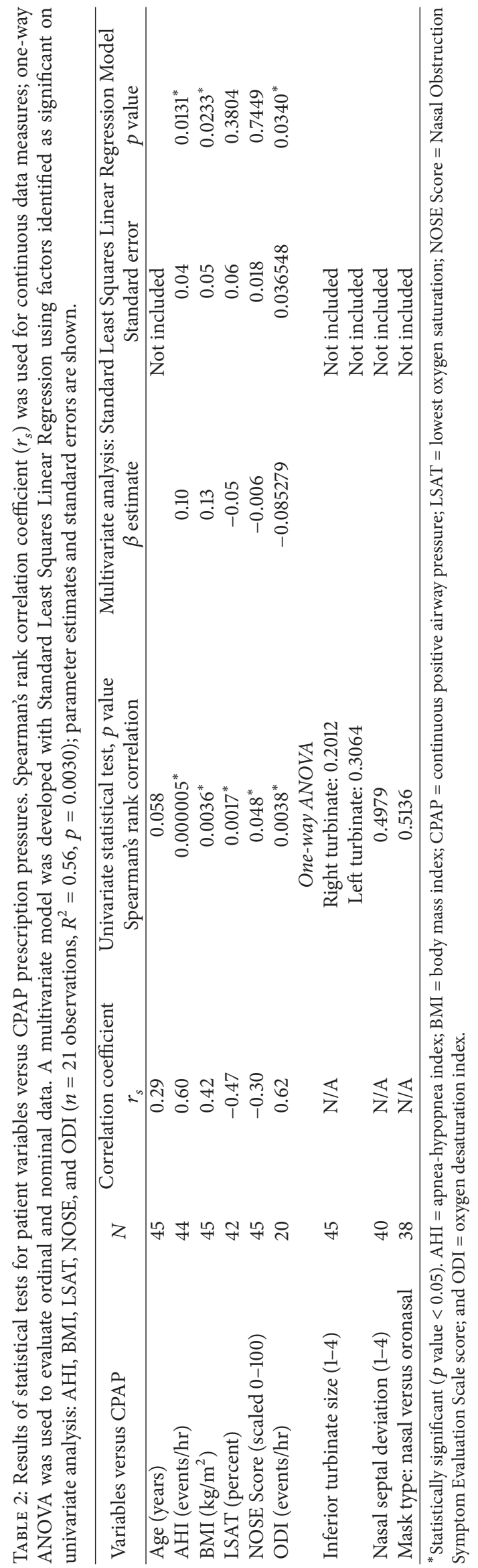


TABLE 3: Therapeutic continuous positive airway pressures, body mass index, and NOSE scale scores stratified by median inferior turbinate sizes. $p$ values from statistical testing with one-way ANOVA are shown.

\begin{tabular}{|c|c|c|c|c|c|}
\hline \multirow{2}{*}{ Variables } & \multicolumn{4}{|c|}{ Median inferior turbinate size: right and left } & \multirow{2}{*}{$p$ value } \\
\hline & Grade 1 & Grade $>1$ to 2 & Grade $>2$ to 3 & Grade $>3$ to 4 & \\
\hline All patients $(N=45)$ & $N=5$ & $N=11$ & $N=21$ & $N=8$ & \\
\hline BMI & $28.1 \pm 4.4$ & $29.1 \pm 6.1$ & $27.7 \pm 4.9$ & $30.6 \pm 9.7$ & 0.8222 \\
\hline CPAP & $12.8 \pm 2.5$ & $11.5 \pm 1.6$ & $11.3 \pm 1.8$ & $12.2 \pm 2.9$ & 0.4599 \\
\hline NOSE Score & $33.0 \pm 25.1$ & $30.0 \pm 18.1$ & $26.0 \pm 25.7$ & $30.4 \pm 20.7$ & 0.8602 \\
\hline Patients w/o nasal obstruction $(N=34)$ & $N=4$ & $N=7$ & $N=18$ & $N=5$ & \\
\hline BMI & $26.8 \pm 3.9$ & $28.8 \pm 7.5$ & $28.0 \pm 5.2$ & $30.3 \pm 11.7$ & 0.8744 \\
\hline CPAP & $13.3 \pm 2.7$ & $11.6 \pm 1.7$ & $11.5 \pm 1.8$ & $12.1 \pm 3.6$ & 0.5213 \\
\hline NOSE Score & $23.8 \pm 16.5$ & $18.9 \pm 11.2$ & $16.8 \pm 12.1$ & $19.5 \pm 11.2$ & 0.7766 \\
\hline Patients with nasal obstruction $(N=11)$ & $N=1$ & $N=4$ & $N=3$ & $N=3$ & \\
\hline BMI & 33.0 & $29.7 \pm 3.3$ & $25.6 \pm 1.9$ & $31.3 \pm 3.2$ & 0.2911 \\
\hline CPAP & 11.0 & $11.3 \pm 1.5$ & $10.0 \pm 0.0$ & $12.5 \pm 0.7$ & 0.4722 \\
\hline NOSE Score & 70 & $49.4 \pm 7.7$ & $80.8 \pm 8.0$ & $57.5 \pm 3.5$ & 0.1125 \\
\hline Patients using nasal mask $(N=27)$ & $N=4$ & $N=7$ & $N=12$ & $N=4$ & \\
\hline BMI & $29.1 \pm 4.3$ & $28.1 \pm 5.8$ & $27.9 \pm 4.2$ & $30.5 \pm 13.5$ & 0.9122 \\
\hline CPAP & $12.3 \pm 2.5$ & $11.9 \pm 1.5$ & $11.4 \pm 1.7$ & $11.9 \pm 4.1$ & 0.9217 \\
\hline NOSE Score & $31.3 \pm 28.7$ & $25.7 \pm 16.3$ & $22.7 \pm 20.4$ & $21.8 \pm 11.4$ & 0.8826 \\
\hline Patients using oronasal mask $(N=11)$ & $N=1$ & $N=4$ & $N=4$ & $N=2$ & \\
\hline BMI & 23.9 & $31.1 \pm 7.0$ & $23.2 \pm 5.4$ & $26.8 \pm 3.2$ & 0.3645 \\
\hline CPAP & 15.0 & $10.8 \pm 1.5$ & $10.9 \pm 2.2$ & $11.0 \pm 1.4$ & 0.2732 \\
\hline NOSE Score & 40 & $37.5 \pm 21.0$ & $33.8 \pm 39$ & $55.0 \pm 7.1$ & 0.8611 \\
\hline
\end{tabular}

$\mathrm{BMI}=$ body mass index in $\mathrm{kg} / \mathrm{m}^{2} ; \mathrm{CPAP}=$ continuous positive airway pressure; $N$ = number of patients; NOSE Score = Nasal Obstruction Symptom Evaluation questionnaire [14].

$\left(r_{s}=0.42\right)$ were moderately correlated. The moderate correlation with BMI is not unexpected as it is logical that a larger person would require more pressure than a thin person given the additional mass in the upper airway and in the abdomen. Two variables, apnea-hypopnea index $\left(r_{s}=\right.$ $0.60)$ and oxygen desaturation index $\left(r_{s}=0.62\right)$, were strongly correlated, which is a logical finding given that a CPAP titration is intended to reduce arousals and to improve oxygenation.

Additional research is needed in order to evaluate whether CPAP therapeutic treatment pressures are truly independent of inferior turbinate sizes. As a retrospective case series utilizing chart review, this study provides level 4 evidence. We would like to encourage researchers to incorporate and use the "Inferior Turbinate Classification System, Grades 1-4" as it is a tool which has high intraand interrater reliability. By using the classification system, the influence that the inferior turbinate sizes have as related to nasal obstruction and CPAP can be more accurately ascertained. Furthermore, despite the lack of an association between CPAP therapeutic treatment pressures and inferior turbinate sizes in patients without nasal surgery we would still recommend that patients with nasal obstruction and large turbinates undergo turbinoplasties as several studies have demonstrated a quality of life benefit and improvement in CPAP use and decreased CPAP in patients who have undergone nasal surgery [10]. Additionally, to our knowledge, this study is the first to evaluate the association between inferior turbinate sizes and therapeutic CPAP; therefore, we caution against making generalizations. In order to increase the level of evidence, we would also encourage prospective case series, case-control, cohort, and even randomized controlled trials. Once several studies have been published, a systematic review and meta-analysis would more accurately answer the question using statistical analysis with random effects modeling.

\section{Limitations}

There are limitations to this study. First, we are limited to the constraints which are shared by all retrospective studies in that only the previously collected data could be utilized and analyzed; therefore, if there are missing data, then patients may have had to be excluded solely based on the lack of documentation. Second, in this study we did not review CPAP device pressures for patients who had previous nasal surgery; however, this was done intentionally given that a meta-analysis of eighteen studies demonstrated a reduction by 2-3 centimeters of water pressure after isolated nasal surgeries [10]. Third, given that we did not have rhinomanometry nor acoustic rhinometry, we were not able to evaluate the relationship between the data from these tools and the inferior turbinate sizes and nasal function as it relates to CPAP; future studies could evaluate these relationships. Lastly, there was no rigid or flexible endoscopy performed in the assessment of these patients as the sleep medicine 
clinics do not have them available; however, each patient underwent a nasal examination by the first author who is a board-certified otolaryngologist.

\section{Conclusion}

In this study, CPAP titration based therapeutic treatment pressures were not found to be associated with inferior turbinate sizes; however, the CPAP therapeutic treatment pressures were strongly correlated with apnea-hypopnea index and oxygen desaturation index.

\section{Disclosure}

(i) There is no financial and no material support for this research and work. (ii) The authors have no financial interests in any companies or other entities that have an interest in the information in Authors' Contribution (e.g., grants, advisory boards, employment, consultancies, contracts, honoraria, royalties, expert testimony, partnerships, or stock ownership in medically related fields).

\section{Disclaimer}

The views herein are the private views of the authors and do not reflect the official views of the Department of the Army or the Department of Defense.

\section{Conflict of Interests}

The authors declare that they have no conflict of interests.

\section{Authors' Contribution}

All authors met the criteria for authorship established by the International Committee of Medical Journal Editors, specifically: Macario Camacho and Soroush Zaghi were responsible for substantial contribution to the conception, design, and statistical analysis and drafting the work, revising the work, and reviewing the paper. Daniel Tran, Sungjin A. Song, Edward T. Chang, and Victor Certal had substantial contributions to the analysis and interpretation of data for the work and revising the work critically for important intellectual content. Additionally, all authors provided final approval of the version to be published and agreed to be accountable for all aspects of the work including that each author ensures the accuracy and/or integrity of the work.

\section{Acknowledgment}

Institution where the work was primarily performed is Stanford Hospital.

\section{References}

[1] M. Camacho, V. Certal, J. Abdullatif et al., "Myofunctional therapy to treat obstructive sleep apnea: a systematic review and meta-analysis," SLEEP, vol. 38, pp. 669-675, 2015.
[2] V. Certal, N. Nishino, M. Camacho, and R. Capasso, "Reviewing the systematic reviews in OSA surgery," Otolaryngology-Head and Neck Surgery, vol. 149, no. 6, pp. 817-829, 2013.

[3] M. Camacho, S. Y. Liu, V. Certal, R. Capasso, N. B. Powell, and R. W. Riley, "Large maxillomandibular advancements for obstructive sleep apnea: an operative technique evolved over 30 years," Journal of Cranio-Maxillofacial Surgery, vol. 43, no. 7, pp. 1113-1118, 2015.

[4] V. Hoffstein, S. Viner, S. Mateika, and J. Conway, “Treatment of obstructive sleep apnea with nasal continuous positive airway pressure: patient compliance, perception of benefits, and side effects," The American Review of Respiratory Disease, vol. 145, no. 4 I, pp. 841-845, 1992.

[5] P. E. Brander, M. Soirinsuo, and P. Lohela, "Nasopharyngeal symptoms in patients with obstructive sleep apnea syndrome. Effect of nasal CPAP treatment," Respiration, vol. 66, no. 2, pp. 128-135, 1999.

[6] J. L. Pepin, P. Leger, D. Veale, B. Langevin, D. Robert, and P. Levy, "Side effects of nasal continuous positive airway pressure in sleep apnea syndrome: study of 193 patients in two French sleep centers," Chest, vol. 107, no. 2, pp. 375-381, 1995.

[7] S. M. Susarla, R. J. Thomas, Z. R. Abramson, and L. B. Kaban, "Biomechanics of the upper airway: changing concepts in the pathogenesis of obstructive sleep apnea," International Journal of Oral and Maxillofacial Surgery, vol. 39, no. 12, pp. 1149-1159, 2010.

[8] N. B. Powell, A. I. Zonato, E. M. Weaver et al., "Radiofrequency treatment of turbinate hypertrophy in subjects using continuous positive airway pressure: a randomized, doubleblind, placebo-controlled clinical pilot trial," The Laryngoscope, vol. 111, no. 10, pp. 1783-1790, 2001.

[9] H.-Y. Li, P.-C. Wang, Y.-P. Chen, L.-A. Lee, T.-J. Fang, and H.C. Lin, "Critical appraisal and meta-analysis of nasal surgery for obstructive sleep apnea," American Journal of Rhinology \& Allergy, vol. 25, no. 1, pp. 45-49, 2011.

[10] M. Camacho, M. Riaz, R. Capasso et al., "The effect of nasal surgery on continuous positive airway pressure device use and therapeutic treatment pressures: a systematic review and metaanalysis," SLEEP, vol. 38, no. 2, pp. 279-286, 2015.

[11] M. Camacho, M. Riaz, A. Tahoori, V. Certal, and C. A. Kushida, "Mathematical equations to predict positive airway pressures for obstructive sleep apnea: a systematic review," Sleep Disorders, vol. 2015, Article ID 293868, 11 pages, 2015.

[12] M. Camacho, S. Zaghi, V. Certal et al., "Inferior turbinate classification system, grades 1 to 4 : development and validation study," The Laryngoscope, vol. 125, no. 2, pp. 296-302, 2015.

[13] R. B. Berry, R. Brooks, C. E. Gamaldo et al., The AASM Manual for the Scoring of Sleep and Associated Events: Rules, Terminology and Technical Specifications, Version 2.0.2, American Academy of Sleep Medicine, Darien, Ill, USA, 2013, http://www.aasmnet.org/.

[14] M. G. Stewart, D. L. Witsell, T. L. Smith, E. M. Weaver, B. Yueh, and M. T. Hannley, "Development and validation of the Nasal Obstruction Symptom Evaluation (NOSE) scale," Otolaryngology-Head and Neck Surgery, vol. 130, no. 2, pp. 157$163,2004$.

[15] T. D. V. Swinscow and M. J. Campbell, Correlation and Regression, BMJ Publishing Group, Southampton, UK, 1997. 


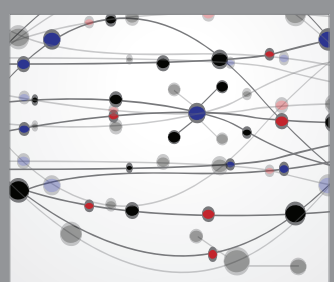

The Scientific World Journal
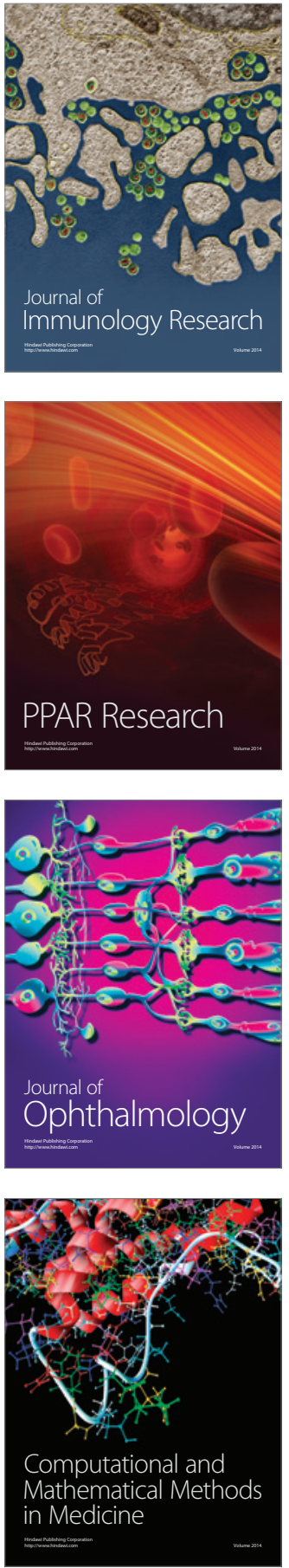

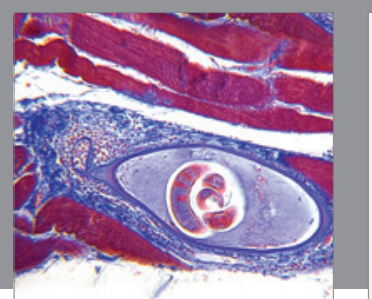

Gastroenterology Research and Practice

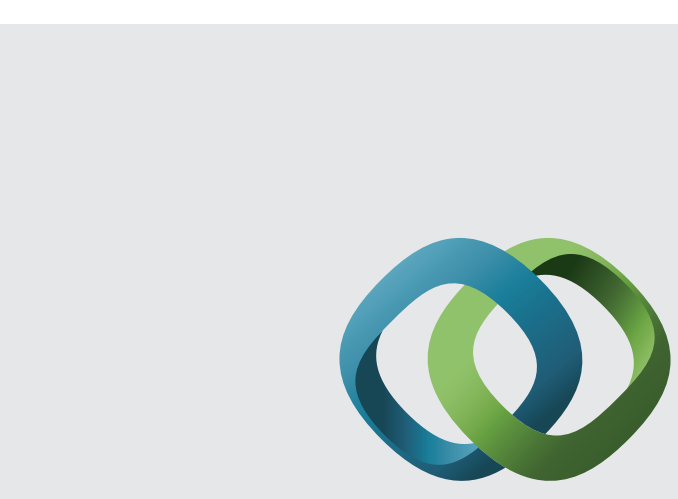

\section{Hindawi}

Submit your manuscripts at

http://www.hindawi.com
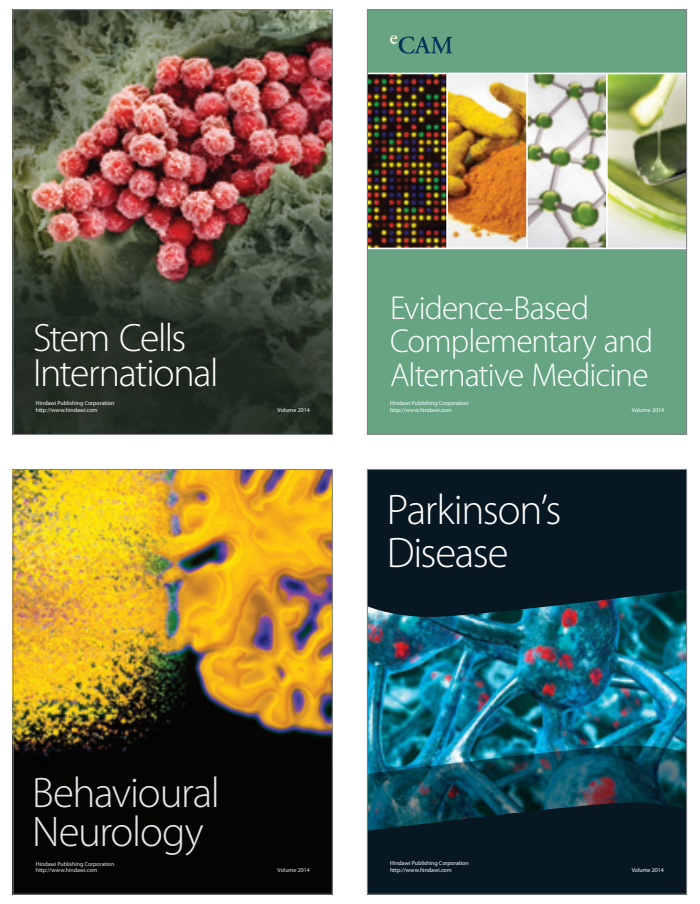
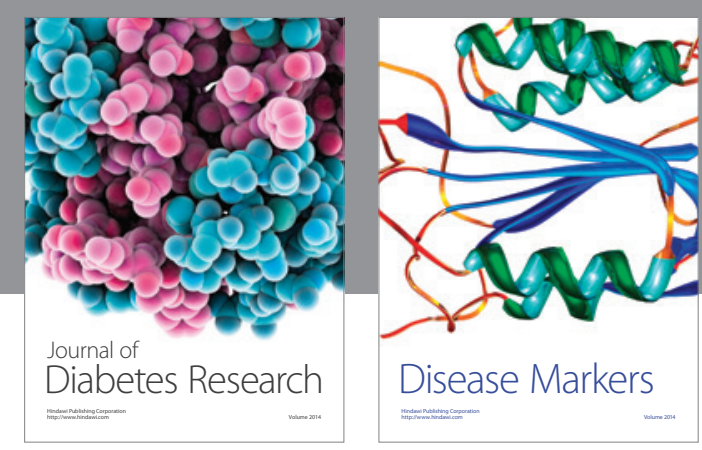

Disease Markers
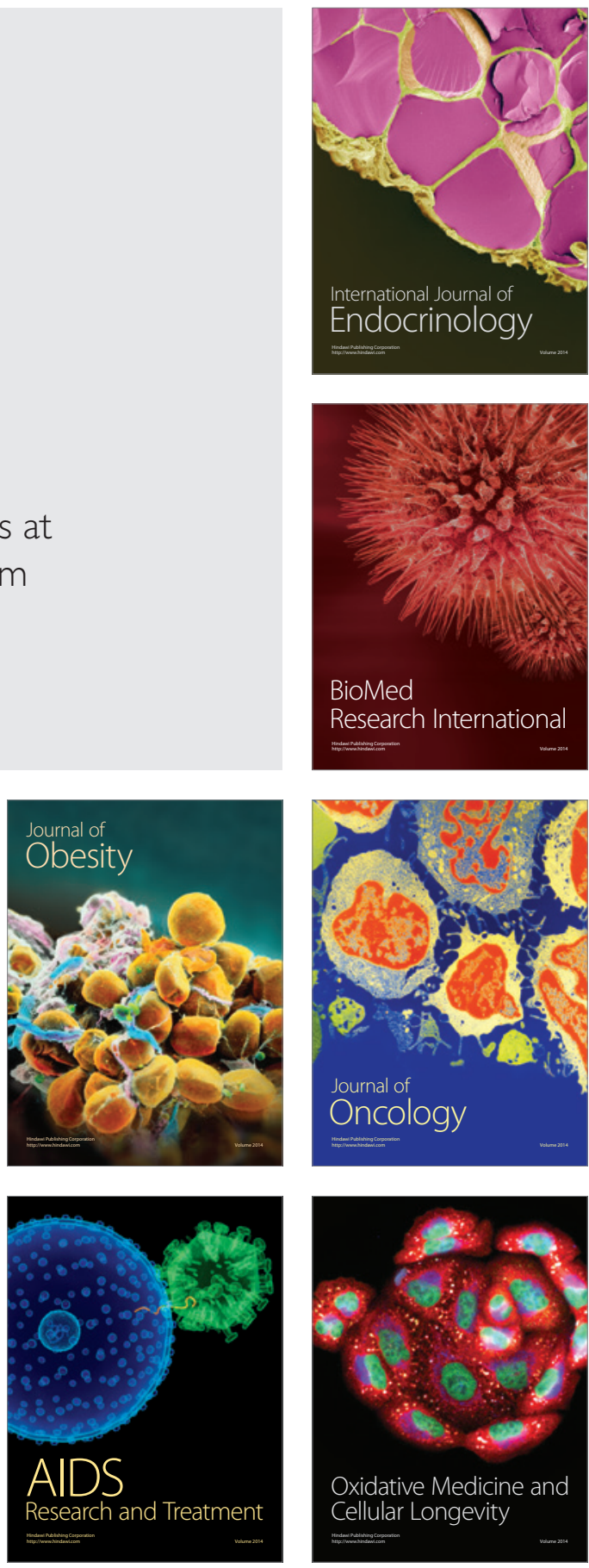